\title{
Os impactos e soluções para os resíduos eletrônicos: Estudo de caso em uma
}

\section{instituição federal de ensino}

\author{
Impacts and solutions for electronic waste: Case study in a federal education institution \\ Impactos y soluciones para los desechos electrónicos: Un estudio de caso en una institución \\ educativa federal
}

Recebido: 20/05/2021 | Revisado: 28/05/2021 | Aceito: 20/07/2021 | Publicado: 28/07/2021

Taissa Alexandrina de Jesus Nascimento ORCID: https://orcid.org/0000-0003-4221-0105 Instituto Federal de Educação, Ciência e Tecnologia do Pará, Brasil E-mail: taissaalexandrina5@gmail.com

Jessyca Karolyny Farias de Sousa

ORCID: https://orcid.org/0000-0003-0502-4215 Instituto Federal de Educação, Ciência e Tecnologia do Pará, Brasil E-mail: jessycakarolyny3@gmail.com

Sarah Brasil de Araújo de Miranda ORCID: https://orcid.org/0000-0001-8955-3362 Instituto Tecnológico Vale, Brasil

E-mail: sarahbrasildam@gmail.com

Diego Raniere Nunes Lima

ORCID: https://orcid.org/0000-0002-8655-9600 Instituto Federal de Educação, Ciência e Tecnologia do Pará, Brasil E-mail:diego.lima@ifpa.edu.br

Gustavo Francesco de Morais Dias

ORCID: https://orcid.org/0000-0002-7681-2318 Instituto Federal de Educação, Ciência e Tecnologia do Pará, Brasil E-mail: gustavo.dias@ifpa.edu.br

\begin{abstract}
Resumo
O estudo apresenta o conhecimento sobre os resíduos eletroeletrônicos (REEE) sendo um estudo de caso dos alunos do IFPA campus parauapebas, o artigo tem como objetivo analisar o conhecimento dos discentes sobre resíduos eletroeletrônicos e produzir um protótipo de ponto de coleta de resíduos eletroeletrônicos. Os resíduos eletroeletrônicos são resíduos descartados com sua vida útil finalizada, na composição desses matériais é encontrado metais perigosos de difícil decomposição e com grande potencial de prejudicar o meio ambiente, se não houver um descarte correto, são muitas vezes jogados em lixo comum ou esquecidos em algum canto da casa, porém eles são recicláveis e podem se tornar matéria prima. $\mathrm{O}$ ponto de coleta pode se tornar um grande aliado na busca de locais adequados para os resíduos, porém a falta de conscientização de grande parte da população sobre os locais necessários para o cuidado desses resíduos é um problema na realidade atual ocasionado pelo intenso aumento da população e pelo avanço tecnológico. Dessa forma, identificou-se a importância da criação de um protótipo com ponto de coleta de REEE para o campus valorizando as cores do campus IFPA e facilitando o entendimento do público alvo sobre a temática. Os resultados alcançados através das análises e respostas dos questionários teve em vista que já existia uma conscientização ambiental sobre esses resíduos, porém no campus não há um ponto de coleta e alguns cursos como o de Eletroeletrônica se mostraram a baixo da média em relação aos conhecimentos sobre a importância dos REEE. De acordo com os resultados do artigo mostra-se a importância da conscientização ambiental dos discentes do campus Parauapebas, a qual pode ser feita com mais disciplinas voltadas para a área do meio ambiente nos diversos cursos como na criação de palestras com toda a comunidade acadêmica.
\end{abstract}

Palavras-chave: Lixo eletrônico; Logística reversa; Ponto de coleta; Parauapebas.

\begin{abstract}
The study presents the knowledge about electronic waste (WEEE) being a case study of students from IFPA campus parauapebas, the article aims to analyze the knowledge of students about electronic waste and produce a prototype of the point of collection of electronic waste. Electro-electronic waste is discarded waste with its final useful life. In the composition of these materials, dangerous metals are found that are difficult to decompose and with a great potential to harm the environment. some corner of the house, but they are recyclable and can become raw material. The collection point can become a great ally in the search for suitable places for waste, however the lack of awareness of a large part of the population about the places necessary for the care of this waste is a problem in the current reality caused by the intense increase of the population. and technological advancement. Thus, the importance of creating a
\end{abstract}


prototype with a WEEE collection point for the campus was identified, valuing the colors of the IFPA campus and facilitating the understanding of the target audience on the subject. The results achieved through the analysis and responses of the questionnaires had in mind that there was already an environmental awareness about these residues, however on the campus there is no collection point and some courses such as Electro-electronics were shown to be below average in relation to knowledge about the importance of WEEE. According to the results of the article, the importance of environmental awareness among students on the Parauapebas campus is shown, which can be done with more disciplines focused on the environment in the various courses, such as the creation of lectures with the entire academic community.

Keywords: Electronic waste; Reverse logistic; Collect point; Parauapebas.

\section{Resumen}

El estudio presenta el conocimiento sobre residuos electrónicos (RAEE) siendo un caso de estudio de estudiantes de IFPA campus parauapebas, el artículo tiene como objetivo analizar el conocimiento de los estudiantes sobre residuos electrónicos y producir un prototipo de punto de recogida de residuos electrónicos. Los residuos electroelectrónicos son residuos de descarte con su vida útil final, en la composición de estos materiales se encuentran metales peligrosos que son difíciles de descomponer y con gran potencial de dañar el medio ambiente, si no hay una disposición correcta, muchas veces se tiran en común. basura u olvidados en algún rincón de la casa, pero son reciclables y pueden convertirse en materia prima. El punto de recogida puede convertirse en un gran aliado en la búsqueda de lugares adecuados para los residuos, sin embargo el desconocimiento de una gran parte de la población sobre los lugares necesarios para el cuidado de estos residuos es un problema en la realidad actual provocado por la intensa aumento de la población y avance tecnológico. Así, se identificó la importancia de crear un prototipo con un punto de recogida de RAEE para el campus, valorando los colores del campus de IFPA y facilitando la comprensión del público objetivo sobre el tema. Los resultados obtenidos a través del análisis y respuestas de los cuestionarios tuvieron en cuenta que ya existía una conciencia ambiental sobre estos residuos, sin embargo en el campus no existe un punto de recolección y algunos cursos como Electro-electrónica se mostraron por debajo de la media en relación al conocimiento sobre la importancia de los RAEE. De acuerdo con los resultados del artículo, se muestra la importancia de la conciencia ambiental entre los estudiantes del campus de Parauapebas, lo que se puede hacer con más disciplinas enfocadas al medio ambiente en los distintos cursos, como la creación de charlas con toda la comunidad académica.

Palabras clave: Basura electronica; Logística inversa; Punto de recogida; Parauapebas.

\section{Introdução}

São muitos os fatos que provam que desde o início da história da sociedade o desenvolvimento conceptivo e seu aumento vem sendo incentivado pela procura incessante pela eficácia. Entretanto, essa eficácia está bem distante da serventia real, a qual está baseada predominantemente na visão econômica. As demais extensões (social, ambiental, cultural e outras) começaram a ser compreendidas como de responsabilidade dos sistemas produtivos há pouco tempo (Andrade et al., 2010).

O que são Resíduos eletroeletrônicos? São todos os produtos que tem como função facilitar a vivência humana, como exemplos temos os eletrodomésticos, tv’s, freezer, celulares, notebook's entre outros. Os eletroeletrônicos são importantes para a vida no dia-a-dia, porém hoje em dia os mesmos duram menos tempo ao compararmos com os eletroeletrônicos mais antigos, os produtos fabricados atualmente tem pouco tempo de vida útil, consequentemente fazendo com que a pessoas comprem pela necessidade, isso é chamado de obsolescência programada e é uma das formas de aumentar o consumo desnecessário fazendo com que as empresas tenham mais lucro (Souza et al., 2018).

A maior parte dos resíduos eletrônicos são de origem natural da informática, o descarte incorreto dos mesmos tem consequências negativas sobre o ambiente por seu material possuir substâncias tóxicas que podem agregar na destruição do ambiente como: mercúrio, chumbo, cádmio. Sendo assim, é necessário um descarte que não prejudique o sistema ecológico e os seres vivos, afinal é preferível que todos vivam em um ambiente ecologicamente equilibrado evitando problemas ao longo do tempo e essa é uma das formas mais sensatas de ver o futuro para as posteriores gerações (Celinski et al, 2013).

Uma forma de reduzir esses indesejados impactos ao ambiente é respeitar a Política Nacional dos Resíduos Sólidos (PNRS) que tem como princípio resolver os problemas oriundos dos resíduos sólidos, sendo assim os matérias que podem ser reutilizados devem ser alvo da logística reversa, na qual os equipamentos voltam para as empresas para que as mesmas deem o tratamento e a destinação final adequada (Brasil, 2010). 
O presente estudo analisou os possíveis impactos e soluções para o lixo eletrônico e a percepção dos alunos dos cursos do Instituto Federal de Educação, Ciência e Tecnologia do Pará - IFPA campus Parauapebas a respeito da temática. Além disso, buscou-se construir um protótipo de ponto de coleta de resíduos eletroeletrônicos para o campus.

\section{Referencial Teórico}

\subsection{Resíduos sólidos}

Para a sociedade moderna um dos seus maiores óbices é o pensamento de uso abusivo sobre a geração de produtos que favorecem a vida dos seres humanos e a forma de como iremos descartar os resíduos sólidos do melhor jeito sem prejudicar o ambiente (Jacobi \& Besen, 2011).

Esse assunto é algo discutido desde a conferência Eco 92, um assunto com grande relevância global, tanto em países desenvolvidos como subdesenvolvidos, por estar envolvido ao grande debate no mundo o aquecimento global e as constantes mudanças de climas. Com isso, se priorizaram novas ideias sobre o gerenciamento e gestão dos resíduos sólidos, na qual estes devem estar alinhados com o setor público, grandes empresas e a sociedade, todos juntos para determinar a forma coerente de descartar os resíduos eletrônicos, sem causar degradação ao sistema ecológico e sustentável (Jacobi \& Besen, 2011).

Podemos citar alguns problemas em destaque nesse plano como: a redução de gases causados pela sociedade e que estão sendo obtidos pelas fontes criadoras, a diminuição dos resíduos no solo, aterros apropriados para este tipo de matérial sem causar degradação, priorizar a reciclagem e a conservação da natureza, e a reutilização sendo a principal medida para a conservação ambiental (Jacobi \& Besen, 2011).

A urbanização acelerada e o rápido adensamento das cidades de médio e grande porte têm provocado inúmeros problemas para a destinação do grande volume de resíduos gerados, condicionando os gestores públicos a adotarem soluções mais eficazes para a gestão dos resíduos sólidos (Doyle \& Alister, 2007).

\subsection{Resíduos eletroeletrônicos}

No século XXI, é notável a discussão sobre o meio ambiente para minimizar os danos ambientais e para manter o uso equilibrado dos recursos naturais não renováveis e renováveis. Sendo que a produção e o desenvolvimento dos eletroeletrônicos e eletrodomésticos tem avançado, intensamente nos últimos anos, com a maior utilização dos recursos naturais. Com o aumento no consumo e o avanço de novas ferramentas tecnológicas mais eficientes e com menor durabilidade, aumenta-se a quantidade de resíduos eletrônicos onde são descartados no meio ambiente sem o tratamento adequando. Consequentemente, o descarte inadequado provoca uma série de danos ambientais e provocando danos à saúde da população (Bursztyn \& Bursztyn, 2006).

Com o surgimento de usuários cada vez mais exigentes, os avanços tecnológicos são necessários e inevitáveis. Quando falamos em tecnologias de informação e comunicação, a inovação é peça chave para conservar-se no mercado. Como consequência deste cenário, houve um acréscimo na quantidade e diversidade de equipamentos ofertados pelas empresas de tecnologia, tornando-os rapidamente obsoletos, configurando uma porcentagem expressiva dos resíduos descartados (Silva, 2012).

A indústria eletroeletrônica tornou-se a maior do mundo, como também a de maior valor agregado. Porém, o final da vida útil destes equipamentos torna-se um problema mundial, devido ao consumo de recursos importantes e elevado potencial de causar danos ao meio ambiente. O REEE é considerado um resíduo perigoso e, devido à presença de substâncias tóxicas, como chumbo, cromo, mercúrio, cádmio, arsênio e bem como retardadores de chama, representa riscos ambientais, ocupacionais e de saúde pública (Silva, 2012). 


\subsection{Logística reversa}

Muitas pessoas, estabelecimentos, empresas, entre outros ao longo de sua produção, não se preocupam com o retorno dos resíduos descartados, deixando-os de lado sem qualquer aproveitamento, fazendo assim com que cada dia mais a situação dos aterros, do ecossistema e do planeta sejam mais preocupantes. A logística reversa, tem como objetivo o retorno desses resíduos ao processo produtivo, dessa forma ela consegue reaproveitar esses materiais e descartar apropriadamente o que antes seria deixado de lado sem qualquer serventia, consequentemente resultando na preservação ambiental (Soares et al., 2016).

A logística reversa é uma área da logística empresarial, ela se preocupa com o retorno dos produtos pós-venda e pósconsumo. Essa logística tem sido usada no combate aos problemas ambientais, ajudando a proteger o meio ambiente por meio da reutilização dos materiais (Chaves et al., 2019). Primeiramente a indústria faz os produtos e suas embalagens, depois disso os produtos são vendidos para outros estabelecimentos e comercializados, com o produto já no estabelecimento ele é vendido para os consumidores, os mesmos utilizam os produtos e as embalagens descartadas, após isso é feita a coleta desses resíduos, que por fim são reciclados e voltam a esse ciclo, resultando na redução da degradação do meio ambiente (Chaves et al., 2019).

Uma questão muito importante sobre o assunto é a obsolescência programada, esse termo se resume basicamente no conceito de um produto que já tem prazo de validade ou um prazo para parar de funcionar, assim as empresas conseguem vender cada vez mais e mais produtos, por conta de que esses produtos irão parar de funcionar mais rápido. Como equipamentos eletrônicos podemos citar: Os computadores, celulares, carregadores e etc, e com o aumento da produção desses eletrônicos a tendência é de que mais produtos possuam obsolescência programada, aumentando assim a importância da implementação da logística reversa para gerar o desenvolvimento de novas mercadorias oriundas de reciclagem (Souza et al., 2018).

Embora a LR (logística reversa) tenha muitos benefícios a empresa que escolhe implementa-lá pode ter problemas, pois não se tem a certeza da disponibilidade dos resíduos após seu ciclo, envolvendo questões financeiras e operacionais. A redução do consumo de energia elétrica, de desperdícios, e geração de empregos são benefícios muito importantes da LR, porém há algumas barreiras que dificultam a implantação da mesma, pois as empresas precisam ter valor social, econômico e valor para o cliente, que não é uma tarefa fácil, pois algumas das empresas no Brasil não prezam pela sustentabilida (Souza et al., 2018).

\subsection{Descarte e reutilização dos resíduos eletrônicos}

O descarte desses materiais eletrônicos muitas vezes são feitos de maneira errada, ocasionando assim impactos negativos ao meio ambiente e aos seres humanos. Primeiramente como exemplo de impactos ao meio ambiente temos: a poluição da água, a qual ocorre devido os equipamentos eletrônicos possuirem metais que se bioacumulam nas cadeias tróficas podendo alcançar os seres humanos através da ingestão de alimentos contaminados e a poluição no solo tendo como consequência problemas causados pela disposição inadequada sem tratamento desses resíduos sobre o solo o contaminando-o com metais pesados (Zorzi \& Bardi, 2019).

Sobre os impactos negativos aos seres humanos existem algumas substâncias produzidas pelos resíduos eletrônicos que podem causar sérios problemas a todos os seres vivos, substâncias como o cádmio, mercúrio e chumbo são algumas delas, que se ingeridas podem acarretar sérios problemas (Zorzi \& Bardi, 2019).

Ao falarmos de reutilização é possível que se pense que ela gera um impacto positivo somente ao meio ambiente (o que é muito importante), porém ao contrário disso a reutilização dos resíduos eletrônicos, também apresenta resultados na sociedade, pois uma parte da população não tem acesso aos equipamentos eletrônicos pelo elevado preço dos novos produtos, a situação seria diferente se parte dos produtos fossem remanufaturados (Souza et al., 2018).

A remanufatura consiste na restauração de peças e componentes de produtos que teriam sua vida útil finalizada, 
fazendo com que essas peças sirvam de matéria-prima para novos produtos. Com a restauração dessas peças, pessoas em classes sociais mais baixas, que não conseguiriam comprar um produto de "primeira mão" ou manufaturado, agora terão mais chance de comprar pois após o processo de inspeção, desmontagem, limpeza e reprocessamento feito na remanufatura os produtos ficam mais baratos, pois os componentes utilizados estão em boas condições porém não são novos (Simonetto et al., 2016). Dessa forma, percebe-se que a reutilização dos resíduos eletrônicos é de essencial importância para a preservação do meio ambiente e cuidado com a vida humana.

\section{Metodologia}

\subsection{Descrição da área de estudo}

No segundo semestre de 2020 foi realizado a revisão bibliográfica e a coletas de dados com os alunos do IFPA campus Parauapebas que ocorreu entre os meses de agosto de 2020 a maio de 2021.

O projeto foi dividido em três etapas, sendo elas: Levantamento bibliográfico, onde foram realizadas pesquisas através de periódicos eletrônicos, acervos de bibliotecas para adquirir mais conhecimento em todos os assuntos citados; a segunda etapa foi a aplicação de um questionário aos discentes do campus buscando conhecer o nível de domínio dos alunos acerca dos resíduos eletroeletrônicos; e a última etapa foi a elaboração de um protótipo de ponto de coleta para esses resíduos eletrônicos.

O questionário foi elaborado por meio da plataforma "google forms" e enviado para as turmas dos alunos do IFPA campus Parauapebas pela ferramenta de comunicação virtual "Whatsapp". Após isso, os discentes responderam algumas perguntas de múltipla escolha sobre o tema resíduos eletrônicos, reutilização e descarte, logística reversa e etc. A partir do levantamento das respostas obtidas foram realizados gráficos que ilustram os resultados.

A delimitação da amostra populacional representativa (Tabela 1), foi realizada a partir do número de todos os alunos regularmente matriculados atualmente no campus de Parauapebas do IFPA.

Tabela 1 - Cursos desenvolvidos pelo IFPA campus de Parauapebas, estudantes regularmente matriculados e amostra entrevistada.

\begin{tabular}{ccc}
\hline Cursos & Alunos matriculados & Amostra entrevistada \\
\hline Meio ambiente (integrado) & 41 & 8 \\
Mecânica (integrado) & 188 & 16 \\
Eletroeletrônica (integrado) & 156 & 19 \\
Eletroeletrônica(subsequente) & 3 & 1 \\
Meio ambiente (subsequente) & 36 & 7 \\
Eletromecânica (subsequente) & 50 & 19 \\
Manutenção de máquinas & 54 & 15 \\
pesadas(proeja) & 100 & 20 \\
Superior de tecnologia em & & $\mathbf{1 0 5}$ \\
automação industrial & $\mathbf{6 2 4}$ & \\
\hline Total & &
\end{tabular}

Fonte: Autores (2021).

Por conta do início da pandemia de covid-19 e suspenção das atividades acadêmicas no campus, o ponto de coleta foi feito de maneira virtual. Para a criação do protótipo utilizou-se o software de criação 3D "sketchup" que tem como finalidade a criação de modelos em 3D no computador, foi elaborado um modelo que mostra a estrutura desse projeto e seus componentes. 


\section{Resultados e Discussão}

O IFPA campus Parauapebas possui em sua maioria cursos voltados para a área industrial, como por exemplo temos os de mecânica, automação industrial e eletroeletrônica, nessas áreas os materiais eletrônicos são bastante utilizados e após seu uso precisa-se perguntar o que acontecerá com tais elementos.

Em busca da resposta para esse questionamento bem como sua solução, analisou-se um meio para que ocorresse a coleta adequada desses resíduos no campus, onde todas os equipamentos depositados pudessem ter a sua destinação correta. Diante disso, o instituto busca demonstrar a preocupação dos alunos e professores com a problemática resíduos eletrônicos e suas consequências presente no município de Parauapebas.

Para a criação do protótipo do ponto de coleta dos resíduos eletrônicos, foram realizadas diversas pesquisas, em busca de inspirações que melhor fossem desenvolver sua parte visual, com o intuito de melhorar seu design houveram diálogos, nos quais foram definidos os elementos presentes no protótipo e como principal base para a sua criação utilizou-se o estudo de Sigrist et al. (2015). Suas divisões foram estabelecidas da seguinte forma: Pilhas, baterias, cartuchos, cabos e acessórios, e equipamentos eletrônicos em geral, como teclados de notebooks, controles, celulares e etc conforme vemos na Figura 1.

Figura 1 - Protótipo do ponto de coleta de resíduos eletrônicos.

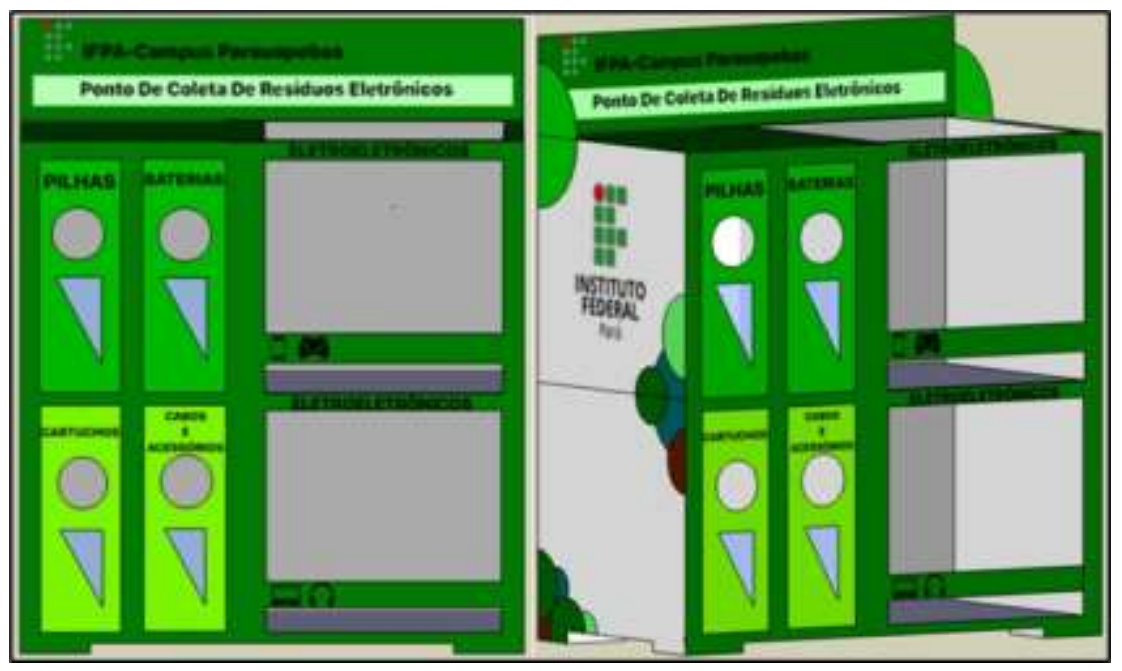

Fonte: Autores (2021).

A imagem acima expõe melhor os detalhes do modelo que foi desenvolvido, como suas cores e detalhes buscando valorizar a identidade institucional do IFPA, sua estrutura e compartimentos que comportam os materiais depositados e seus textos que usam linguagem verbal e não-verbal para que facilite a compreensão de aonde depositar cada resíduo. Além disso, com a possível criação do modelo físico também será utilizada a linguagem em braile para facilitar a disposição dos resíduos eletrônicos por deficientes visuais.

Em relação ao conhecimento dos estudantes a respeito da temática a pesquisa foi feita através de um questionário disponível a todos os alunos do Campus Parauapebas no formato virtual, através da plataforma online Google forms, as perguntas foram direcionadas apenas para os alunos do campus e foi respondido pelos alunos que se sentiram dispostos em contribuir com a pesquisa. A primeira pergunta foi a respeito do conhecimento sobre o que são resíduos eletrônicos (Figura 2). 
Figura 2 - Pergunta sobre o que são resíduos eletrônicos aos discentes de cada curso do IFPA campus Parauapebas.

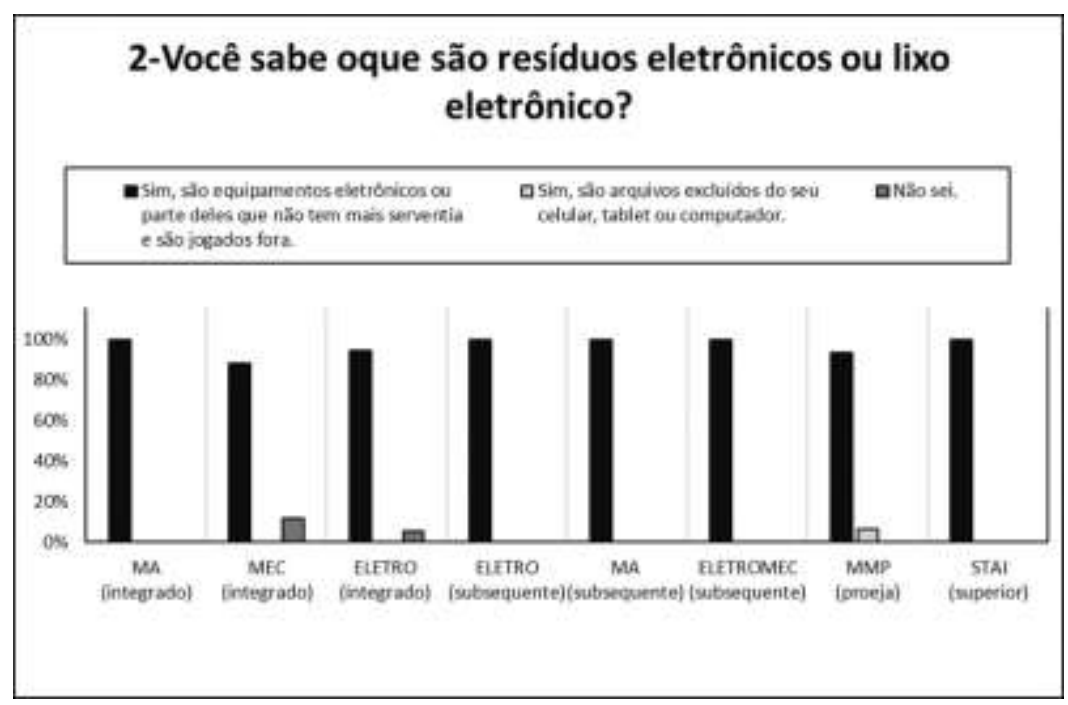

Fonte: Autores (2021).

Com relação as siglas MA é a sigla referente ao curso de meio ambiente integrado e subsequente; MEC é a sigla referente ao curso de mecânica integrado; ELETRO refere-se ao curso de eletroeletrônica integrado; ELETROMEC referente ao curso de eletromecânica subsequente; MMP referente ao curso de máquinas pesadas proeja; STAI referente ao curso de superior em tecnologia e automação industrial.

O conhecimento do que são resíduos eletrônicos é positivo, podemos observar que o número de discentes que sabem e entendem a base do que é lixo eletrônico é um número superior entre $80 \%$ e 100\%, enquanto a taxa de pessoas que não sabiam ou acreditavam ser arquivos tecnológicos foram a minoria. Entre eles estão MEC integrado, ELETRO integrado e MMP proeja, chegando próximo a $0 \%$.

$\mathrm{Na}$ atualidade um dos maiores problemas que envolvem o meio ambiente são a grande quantidade de resíduos gerados, por motivos do crescimento da população e a necessidade por produtos que atendem suas vontades (Spengler et al., 2018). Logo, o conhecimento sobre o que são REEE é importante para as pessoas poderem saber o seu impacto no meio ambiente e sociedade.

Foi indagado também aos alunos do IFPA campus Parauapebas sobre os danos causados pelo descarte inadequado dos resíduos eletrônicos (Figura 3). 
Figura 3 - Pergunta sobre quais os danos causados pelo descarte inadequado dos resíduos eletrônicos aos discentes de cada curso do IFPA campus Parauapebas.

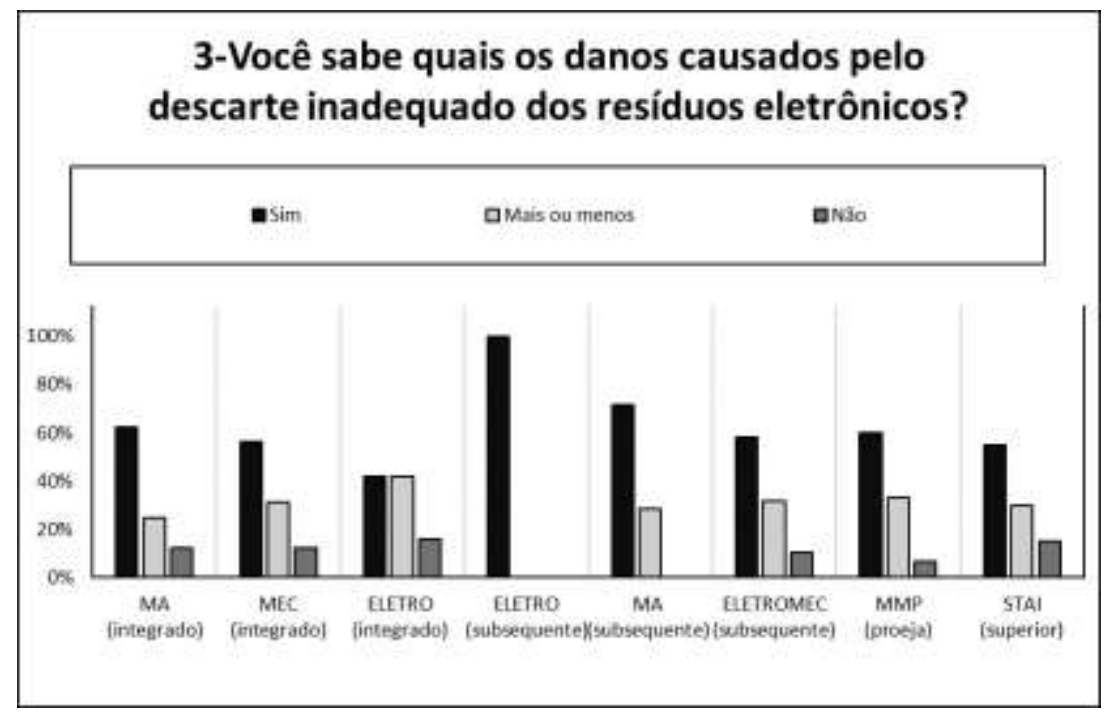

Fonte: Autores (2021).

Com o avanço e desempenho de máquinas a utilização das mesmas são mais que necessarias nos dias de hoje, porém a utilização excessiva aumentou o seu consumo e consequentemente os resíduos também aumentaram de forma alarmante.

A ONU relatou sobre o tema e mostrou que no ano de 2016 a quantidade global de lixo eletrônico acumulado estava em aproximadamente 44,7 milhões de toneladas, o que equivale a mais de 4.500 torres Eiffel (Baldé et al., 2017). Até 2030 a quantidade de resíduos deve aumentar para cerca de 74,7 milhões de toneladas, esse crecimento corresponde a quase o dobro de 16 anos atrás (Baldé et al., 2017).

Observamos que os resutados do gráfico estão intercalados em relação a pergunta "Você sabe quais os danos causados pelo descarte inadequado dos resíduos eletrônico?”, contudo é um número significativo de discentes que acreditam que sim, que o descarte incorreto pode trazer danos, ficando entre $40 \%$ e $100 \%$. Entretanto o número de pessoas que ficaram incertas e colocaram mais ou menos ficou entre $0 \%$ a $40 \%$, já em relação a não saber quais danos que o descarte incorreto traz o resultado foi relativamente baixo na maioria dos cursos.

A turma de ELETRO subsequente foi a única em que todos os alunos respoderam sim, enquanto ELETRO Intregado ficou dividida em sim e mais ou menos, poucos alunos respoderam não. Dessa forma, vemos que em cursos com matriz semelhante pode haver grande divergência de conhecimento em temas específicos, como no caso dos resíduos eletrônicos.

Foi perguntado em seguida aos alunos do campus Parauapebas sobre o seu conhecimento a respeito da logística reversa (Figura 4). 
Figura 4 - Pergunta sobre o conhecimento a respeito da logística reversa aos discentes de cada curso do IFPA campus Parauapebas.

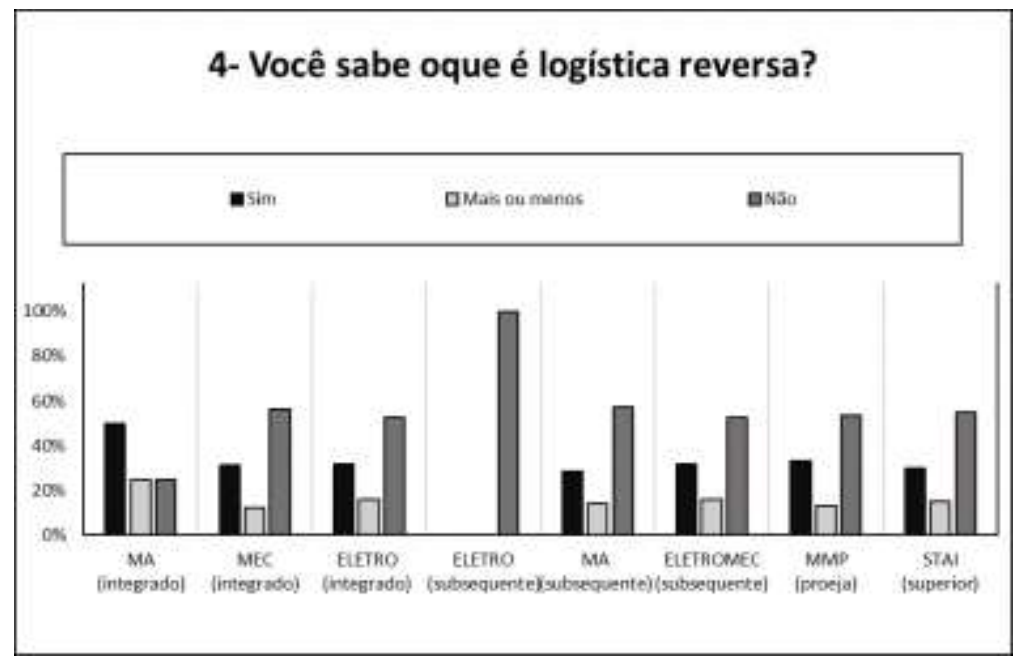

Fonte: Autores (2021).

Podemos observar através do gráfico da Figura 4 que grande parte dos alunos do campus não conhecem o que é logística reversa, ficando entre as porcentagens $50 \%$ na grande maioria dos cursos. Apesar disso houve alguns estudantes que responderam que sim, que conheciam a logística reversa como o meio ambiente integrado, no qual a maioria dos alunos respondeu conhecer sobre a temática, isso provavelmente se deve ao fato de o curso ter na sua matriz curricular a disciplina de Gerenciamento dos Resíduos Sólidos, na qual é trabalhada questões voltadas para a logística reversa. Bem diferente do curso de meio ambiente no curso de ELETRO subsequente todos responderam que não conheciam a logística.

A logística reversa é algo bem importante para as indústrias e empresas, pois ela visa uma solução mais sustentável para estas, de forma que o meio ambiente não seja prejudicado através dos equipamentos obsoletos, buscando coletar esses equipamentos no seu pós consumo. Por isso, são necessários processos que certifiquem que a logística reversa dos resíduos eletrônicos está ocorrendo de forma adequada nos municípios (Celinski et al., 2013).

Buscando identificar a conscientização dos alunos sobre o tema se perguntou sobre se os mesmos comprariam equipamentos eletrônicos que tivessem peças oriundas de reciclagem (Figura 5).

Figura 5 - Pergunta sobre a possível compra de equipamentos eletrônicos que tenham peças oriundas da reciclagem aos discentes de cada curso do IFPA campus Parauapebas.

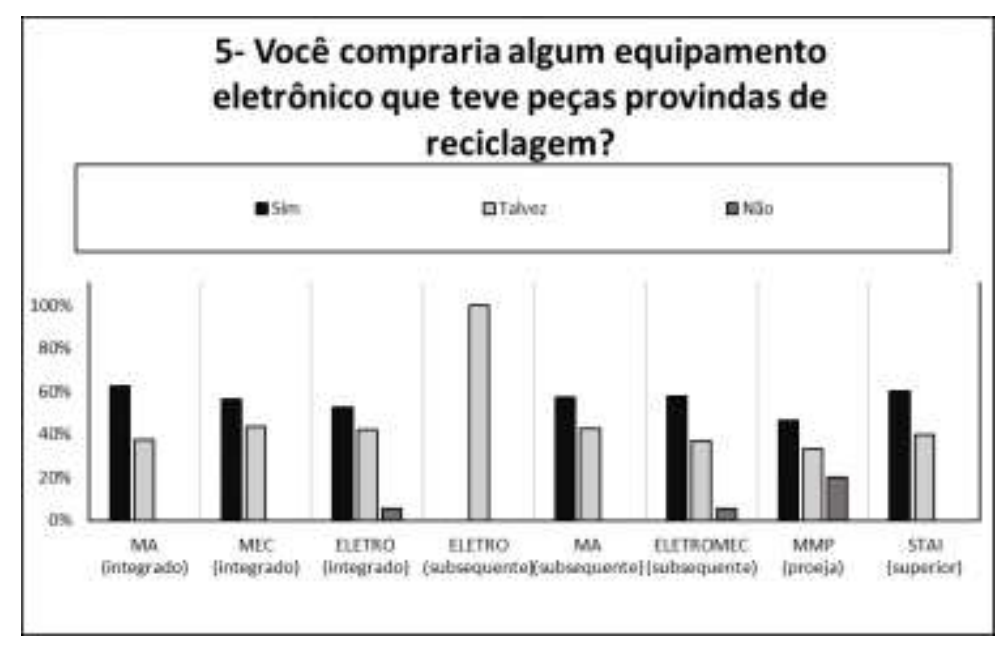

Fonte: Autores (2021). 
Um número significativo de discentes responderam com sim, que comprariam produtos com peças recicláveis, ficando entre 50\% a 60\% na maioria dos cursos, contudo o talvez ganhou força chegando em $100 \%$ na turma de ELETRO subsequente. Já em relação ao não como resposta ao questionamento foi bem baixa a porcentagem no máximo a $20 \%$ no curso de maquinas pesadas.

A empresa chinesa Huawei tem trabalhado para promover a logística reversa: entre 2017 e março de 2019, mais de 850 toneladas de equipamentos da marca foram reaproveitadas no território brasileiro. A reciclagem é feita em Sorocaba na fábrica da empresa, em colaboração com o Grupo Reciclo (Huawei, 2019).

Porém essa prática ainda é pouco utilizada pelas empresas, já que necessitam de um planejamento estratégico e específico e capital alto (Vieira et al., 2009). No entanto para Gerbase e Oliveira (2012) existe a oportunidade da reciclagem e a recuperação do valor investido economicamente nos resíduos, pois existe uma quantidade bem significativa de metais valiosos em seu interior.

Buscando analisar o interesse e preocupação dos alunos pela temática perguntou-se sobre a importância da instalação de um ponto de coleta de resíduos eletrônicos no campus Parauapebas (Figura 6).

Figura 6 - Pergunta sobre a importância do ponto de coleta de resíduos eletrônicos aos discentes de cada curso do IFPA campus Parauapebas.

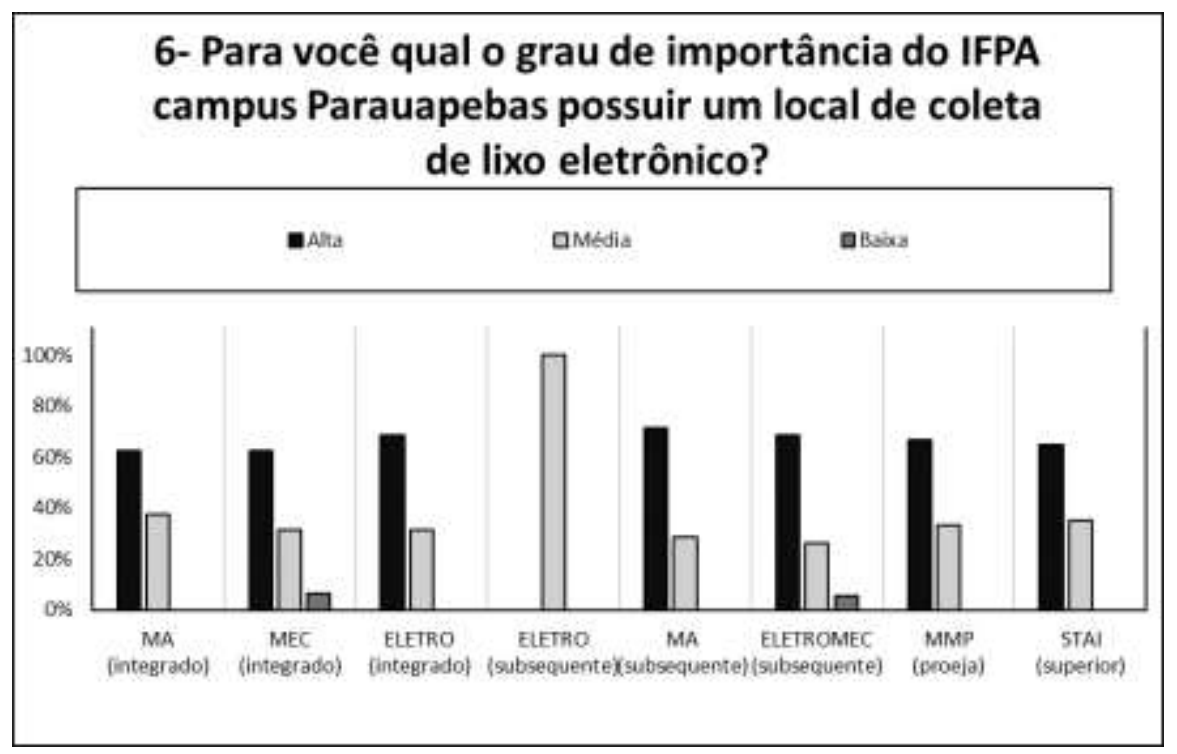

Fonte: Autores (2021).

Por ser uma instituição de ensino de cursos técnicos e superior que capacita pessoas para a indústria e para promover o desenvolvimento sustentável é importante se criar um local de depósito para os resíduos eletrônicos usados para serem enviados para o local adequado para reutilização e tratamento.

Nesse sentido, grande parte dos alunos acreditam que é necessário um local de descarte para o lixo eletrônico no campus Parauapebas, a maioria dos cursos respondeu ser alta a importância desse ponto, aproximadamente $60 \%$, como pode ser visto no gráfico da figura 6. Porém a porcentagem de média, é bem significativa também, esta ficou entre $30 \%$ dos discentes de cada curso. Contudo a turma de ELETRO subsequente foi totalmente na opção de média para a necessidade de um local de coleta para o lixo eletrônico. E duas turmas apresentaram que a necessidade é baixa para um local de coleta, mas em pequena porcentagem a turma de MEC integrado e a turma de ELETROMEC subsequente ficando em aproximadamente $10 \%$.

Também se perguntou sobre a contaminação do meio ambiente e dos seres humanos pelos resíduos eletrônicos aos discentes de cada curso do IFPA campus Parauapebas (Figura 7). 
Figura 7 - Pergunta sobre a contaminação do meio ambiente e dos seres humanos pelos resíduos eletrônicos aos discentes de cada curso do IFPA campus Parauapebas.

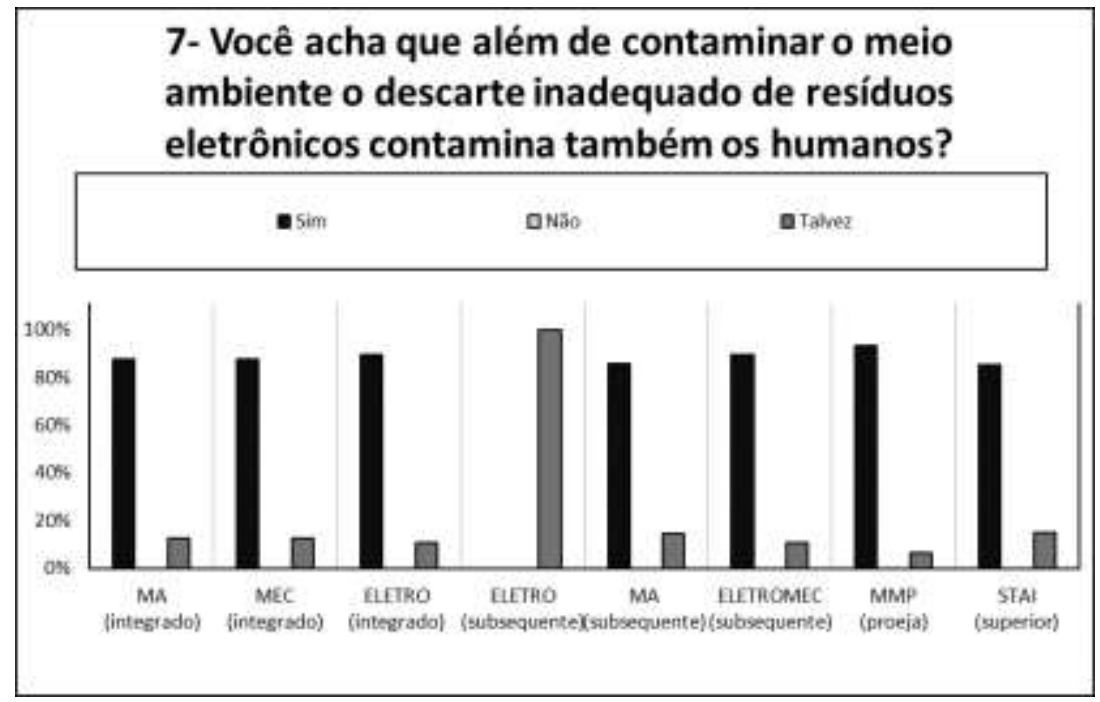

Fonte: Autores (2021).

A grande maioria dos alunos de cada curso responderam que sim, o descarte incorreto pode causar danos aos humanos entre, porém houve pessoas que responderam ao questionário com o talvez entre 0 a $10 \%$ dos alunos de cada curso, e todos os estudantes do curso ELETRO subsequente responderam com talvez. Nenhum aluno respondeu com "não", o que demonstra um leve conhecimento pelo menos por parte dos que responderam talvez.

Os Resíduos eletrônicos provocam vários problemas devido terem em sua composição metais pesados, os quais podem gerar problemas à saúde pública e reduzir o tempo de vida útil de aterros sanitários. Tratar dos resíduos eletrônicos nos dias de hoje é um dos principais obstáculo que as três esferas do poder público e a iniciativa privada enfrentam quando o assunto é construir uma sociedade ecologicamente sustentável (Rodrigues et al., 2007).

Segundo Silva Júnior et al. (2020), ressaltam que os danos à saúde humana vão de perda do olfato, da audição e da visão, até o enfraquecimento ósseo. Grande parte dos consumidores e grandes empresas não tem consciência das consequências, muitos também não possuem informações necessárias sobre reciclagem de lixo eletrônico e seu impacto no meio ambiente. O perigo de lançar esses produtos no solo ou na água é grande, pois esses resíduos contêm chumbo, cádmio e mercúrio, esses metais presentes no interior de algumas pilhas e baterias por exemplo, podem contaminar o solo, rios e chegar aos seres humanos.

\section{Considerações Finais}

A partir da aplicação dos questionários identifica-se que a percepção dos discentes do IFPA ainda é limitada no aspecto geral em relação aos resíduos eletrônicos, o que implica na falta de sensibilidade sobre seu papel diante dos impactos gerados pelo inadequado condicionamento dos resíduos.

Os resultados obtidos com o desenvolvimento do protótipo do ponto de coleta foram promissores, pois iniciaram o processo de conscientização sobre a importância do condicionamento adequado dos resíduos eletrônicos. O design do ponto de coleta idealizado após os testes realizados com o protótipo foi finalizado. A partir disso, buscara-se na próxima etapa identificar as melhores matérias para a construção levando em conta redução de custos e maior facilidade de transporte.

Embora, a grande maioria dos discentes tenham interesse em mudar seus hábitos na segregação de seus resíduos, torna-se de suma importância intervenções que auxiliarão a disseminar esse comportamento pró-ambiental nas instituições 
públicas. Tais como atividades práticas, palestras e ações voltadas para conscientização sobre os temas coleta seletiva, logística reversa, resíduos eletrônicos e entre outros, bem como formalizar parcerias com cooperativas e empresas que possam tratar esses resíduos.

Além disso, a percepção da comunidade acadêmica do IFPA Campus Parauapebas, pode ser melhorada por meio de atividades de educação ambiental e inclusão de matérias relacionadas ao meio ambiente na estrutura curricular de todos os cursos da instituição. Dessa forma, futuramente a universidade terá alunos mais instruídos e preocupados com a situação tanto da coleta seletiva como do meio ambiente dentro e fora do órgão. Simples ações como o incentivo ao aprendizado ambiental podem formar futuros cidadãos mais responsáveis com o meio ambiente.

Para a solução cabível e aplicável na nossa região em especial onde o projeto foi pesquisado em Parauapebas é preciso que haja uma fiscalização mais rígidas nas empresas da região. Para estudos futuros é importante a criação de um ponto de coleta de resíduos eletrônicos na instituição, a fim de identificar a quantidade e tipos de resíduos que mais são descartados pela comunidade acadêmica.

\section{Agradecimentos}

Ao CNPq, pela bolsa concedida que possibilitou a realização desse estudo e ao IFPA campus Parauapebas pelo suporte para a pesquisa.

\section{Referências}

Andrade, R., Fonseca, C., \& Mattos, K. (2010). Geração e destino dos resíduos eletrônicos de informática nas instituições de ensino superior de natalrn. HOLOS, 2, 100-112.

Baldé, C. P., Forti, V., Gray, V., Kuehr, R., \& Stegmann, P. (2017). The Global E-Waste Monitor,1-116.

Brasil. 2010. Lei n. 12.305 de 2 de agosto de 2010 (2010). Dispões sobre a criação da Política Nacional de Resíduos Sólidos - PNRS.

Bursztyn, M. A. A., \& Bursztyn, M. (2006). Desenvolvimento sustentável: biografia de um conceito. In: Nascimento, E. P., Vianna, J. N. (Org.) Economia, meio ambiente e comunicação. Rio de Janeiro: Garamond.

Celinski, T. M., Cerutti, D. M. L., Ielo, G. P. F., Celinski, V. G., \& Cerutii, I. A. (2013). Gestão do Lixo Eletrônico: Desafios e Oportunidades. Congresso Brasileiro de Gestão Ambiental, 1-4.

Chaves, G. L. D., Balista, W. C., \& Comper, I. C. (2019). Logística reversa: o estado da arte e perspectivas futuras. Engenharia Sanitária e Ambiental, 24 (4), $821-831$.

Doyle, A. (2007). Nova aliança para combater as montanhas de lixo eletrônico. Reuters. <http://www.hsm.com.br/canais/notic.php?marca busca=reciclagem\#marcabusca>.

Gerbase, A. E., \& Oliveira, C. R. (2012). Reciclagem do lixo de informática: uma oportunidade para a química. Química Nova, 35(7), 1486-1492.

Huawei. (2019). Huawei Togheter: Building a Better Connected Brazil. https://www.teleco.com.br/huawei/revistas/Revista.Together.A3N8.pdf>.

Jacobi, P. R., \& Besen, G. R. (2011). Gestão de resíduos sólidos em São Paulo: desafios da sustentabilidade. Estudos Avançados, $25(71)$, $135-158$.

Rodrigues, A. C. (2007). Impactos Socioambientais dos resíduos de equipamentos Elétricos e Eletrônicos: Estudo da Cadeia Pós-consumo no Brasil. Dissertação (mestrado) em faculdade de engenharia, arquitetura e urbanismo, 1-321.

Silva, M. B. O. (2012). Obsolescência programada e teoria do decrescimento versus direito ao desenvolvimento e ao consumo (sustentáveis). Veredas do direito - direito ambiental e desenvolvimento sustentável, 9 (17), 181-196.

Sigrist, C. S. L. et al. (2015). Desenvolvimento de ponto de coleta de resíduos eletroeletrônicos. Revista Eletrônica em Gestão, Educação e Tecnologia Ambiental, 19(2), 1423-1438.

Silva Júnior, V. M. et al. (2020). Percepção sobre o lixo eletrônico: estudo de caso em uma Instituição Federal de Ensino. Research, Society and Development, 9(11), 1-14.

Simonetto, E. O., Putnik, G., Rodrigues, G. O., Alves, C., \& Castro, H. (2016). Um modelo de dinâmica de sistemas para avaliação do reaproveitamento de resíduos eletrônicos na remanufatura de computadores em uma instituição de ensino superior. Exacta - EP, 14 (3), $385-402$.

Soares, I. T. D., Streck, L., Trevisan, M., \& Madruga, L. R. R. G. (2016). Logística reversa: uma análise de artigos publicados na base spell. Revista de Gestão Ambiental e Sustentabilidade - GeAS, 5 (2), 76-97. 
Research, Society and Development, v. 10, n. 9, e33910916321, 2021

(CC BY 4.0) | ISSN 2525-3409 | DOI: http://dx.doi.org/10.33448/rsd-v10i9.16321

Souza, E. D., Hammes, G., \& Rodriguez, C. M. T. (2018). Barreiras na implementação da logística reversa nas empresas catarinenses. South American Development Journal Society, 04 (11), 195-213.

Spengler, A. I., Nunes, J. G., \& Ferreira, D. M. M. (2018). Determinação da composição gravimétrica de resíduos sólidos de feira em Sorris - MT. In: Congresso Sul - Americano de Resíduos Sólidos e Sustentabilidade, IBEAS, 1-6.

Vieira, K. N., Soares, T. O. R., \& Soares, L. R. (2009). A Logística Reversa do Lixo Tecnológico: um estudo sobre o projeto de coleta de lâmpadas, pilhas e baterias da Brasken. Revista de Gestão Social e Ambiental, 3 (3), 120-136.

Zorzi, L., \& Bardi, M. A. G. (2017). Resíduos eletrônicos: um estudo da geração e descarte de resíduos eletrônicos pela população da região de Itatiba-SP. Revista Ensaios Pioneiros, 01 (01), 58-70. 